\title{
MATHEMATICAL MODELING OF THERMAL INFLUENCE FROM FOREST FIRE FRONT ON A CONIFEROUS TREE TRUNK
}

\author{
Nikolay V. Baranovskiy ${ }^{1,}$, Vladimir B. Barakhnin ${ }^{2,3}$ and Ksenia N. Andreeva ${ }^{1}$ \\ ${ }^{1}$ National Research Tomsk Polytechnic University, 634050 Tomsk, Russia \\ ${ }^{2}$ Novosibirsk State University, High School of Informatics, 630090, Novosibirsk, Russian Federation \\ ${ }^{3}$ Institute of Computational Technologies, Siberian Branch of Russian Academy of Science, 630090, Novosibirsk, \\ Russian Federation
}

\begin{abstract}
Numerical research results of heat transfer in layered tree trunk influenced by heat flux from forest fire presented. The problem solved in two-dimensional statement in Cartesian system of co-ordinates. The typical range of influence parameters of heat flux from forest fire considered. Temperature distributions in different moments of time obtained. Condition of tree damage by forest fire influence is under consideration in this research.
\end{abstract}

\section{Introduction}

Last decades forest fires have turned from the natural regulating factor to the catastrophic phenomenon which causes an economic, ecological and social damage [1]. There is their damage, fragmentation, destruction as a results of influence of forest fires on forest stands [2,3]. Development of fire impact (influence on forest ecosystems, especially, on forest stands) monitoring and forecasting technologies is prominent aspect along forecasting of forest fire danger [4].

Now overwhelming majority of papers devoted to the analysis of an actual statistical material on forest fires incidents and their ecological consequences [5,6]. However, development of information systems of forest stands geoecological monitoring at active forest fires on the basis of physically proved mathematical models of heat transfer in structure of the trees $[7,8]$ forming a forest stand can become one of perspective directions.

Purpose of the present paper is mathematical simulation of heat transfer processes in structure of a coniferous tree trunk at influence of radiation from the forest fire front in flat statement.

\section{Physical and Mathematical Statements}

The research objective can be reached by the decision of following problems:

1. The formulation of physical model,

2. Development of mathematical model,

3. Numerical research of mathematical model.

${ }^{\text {a }}$ Corresponding author: firedanger@yandex.ru 
The mathematical model developed taking into account following assumptions and suggestions. Separately standing tree of coniferous breed (for definiteness a pine) is considered. Only tree trunk under consideration and presence of branches not considered. The trunk accepted by three-layer structure, which consist of bark, subcrustal layer and core. Thermophysical characteristics of a material of layers do not depend on temperature. Influence of moisture evaporation from external layers and inside the trunk was neglected. Geometry of decision area presented on fig. 1.

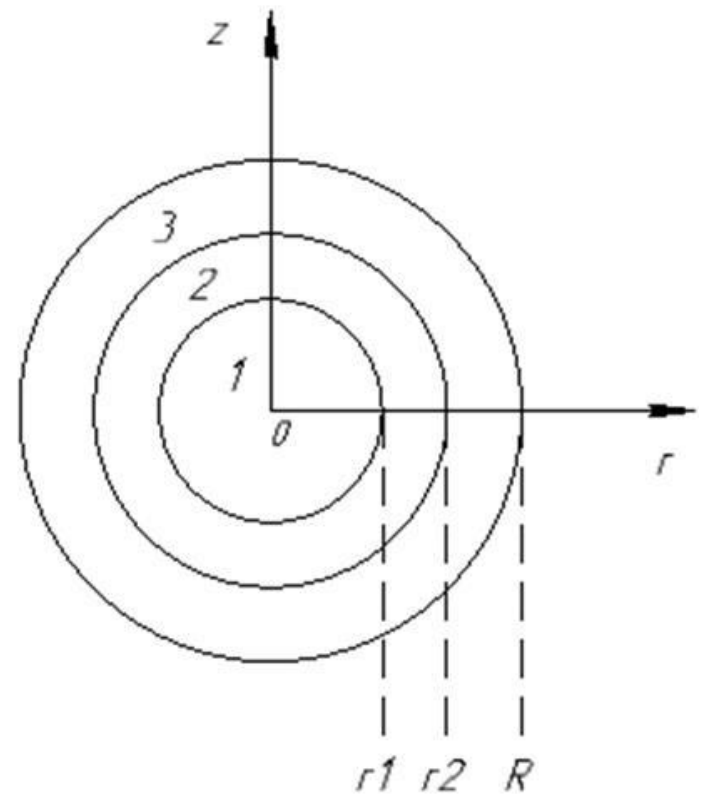

Figure 1. The scheme of decision area.

Heat transfer processes in layered structure of a tree described by the non-stationary differential equations of heat conductivity with corresponding initial and boundary conditions:

$$
\begin{gathered}
\rho_{1} c_{1} \frac{\partial T_{1}}{\partial t}=\frac{\lambda_{1}}{r} \frac{\partial}{\partial r}\left(r \frac{\partial T_{1}}{\partial r}\right)+\frac{\lambda_{1}}{r^{2}} \frac{\partial^{2} T_{1}}{\partial \varphi^{2}} \\
\rho_{2} c_{2} \frac{\partial T_{2}}{\partial t}=\frac{\lambda_{2}}{r} \frac{\partial}{\partial r}\left(r \frac{\partial T_{2}}{\partial r}\right)+\frac{\lambda_{2}}{r^{2}} \frac{\partial^{2} T_{2}}{\partial \varphi^{2}} \\
\rho_{3} c_{3} \frac{\partial T_{3}}{\partial t}=\frac{\lambda_{3}}{r} \frac{\partial}{\partial r}\left(r \frac{\partial T_{3}}{\partial r}\right)+\frac{\lambda_{3}}{r^{2}} \frac{\partial^{2} T_{3}}{\partial \varphi^{2}} \\
\mathrm{r}=\mathrm{R}, \varphi \in\left(\varphi_{1}, \varphi_{2}\right),-\lambda_{1} \frac{\partial T_{1}}{\partial r}=q_{f f} \\
\mathrm{r}=0,-\lambda_{1} \frac{\partial T_{1}}{\partial r}=0,1
\end{gathered}
$$




$$
\begin{gathered}
\varphi=0,-\lambda_{i} \frac{\partial T_{i}}{\partial \varphi}=0, \\
\varphi=\pi-\lambda_{i} \frac{\partial T_{i}}{\partial \varphi}=0, \\
\mathrm{r}=\mathrm{R} 1,-\lambda_{1} \frac{\partial T_{1}}{\partial r}=-\lambda_{2} \frac{\partial T_{2}}{\partial r}, T_{1}=T_{2}, \\
\mathrm{r}=\mathrm{R} 2,-\lambda_{2} \frac{\partial T_{2}}{\partial r}=-\lambda_{3} \frac{\partial T_{3}}{\partial r}, T_{2}=T_{3},
\end{gathered}
$$

where $T_{i}, \rho_{i}, c_{i}, \lambda_{i}$ - temperature, density, thermal capacity and heat conductivity of tree layers (1 core, 2 - subcrustal layer, 3 - bark). r, $\varphi$ - spatial coordinates. $t$ - time coordinate. $q_{f f}$ - radiant thermal flux from forest fire front.

The problem solved by method of final differences. The multidimensional differential equations solved by a locally-one-dimensional method. The marching method used for the decision of finite difference analogues of equations [9]. Data of experimental fires, which were spent by employees of Institute of forest of the Siberian Branch of the Russian Academy of Science in vicinities of Krasnoyarsk, used for development of the basic scenarios of influence of a radiant thermal flux from forest fire front. Dependence [10] used for an estimation of value of the thermal flux from forest fire front:

$$
y=326,37 e^{-0.2791 x},
$$

where $\mathrm{x}$ - distance to a fire edge, $\mathrm{m}$. $\mathrm{y}$ - density of a thermal flux, $\mathrm{kW} / \mathrm{m}^{2}$.

\section{Results and Discussion}

Numerical realization of mathematical model of heat transfer in layered structure of coniferous tree trunk carried out in the programming language of high level Object Pascal. The computer like IBM PC with two-core central processor Intel Pentium $3 \mathrm{GHz}$ and operative memory $8 \mathrm{~GB}$ was used for computational experiments. The one-dimensional mathematical model allows developing resource effective algorithm for program realization. Verification of one-dimensional problem spent using in the present work of flat statement in polar coordinates. Heat transfer processes calculation using onedimensional model occurs in a mode advancing real time of development of process. It allows to say, that the one-dimensional mathematical model has prospects for use in modern information systems. Temperature distributions in layered structure of tree trunk to the various moments of time presented in drawing 2. 

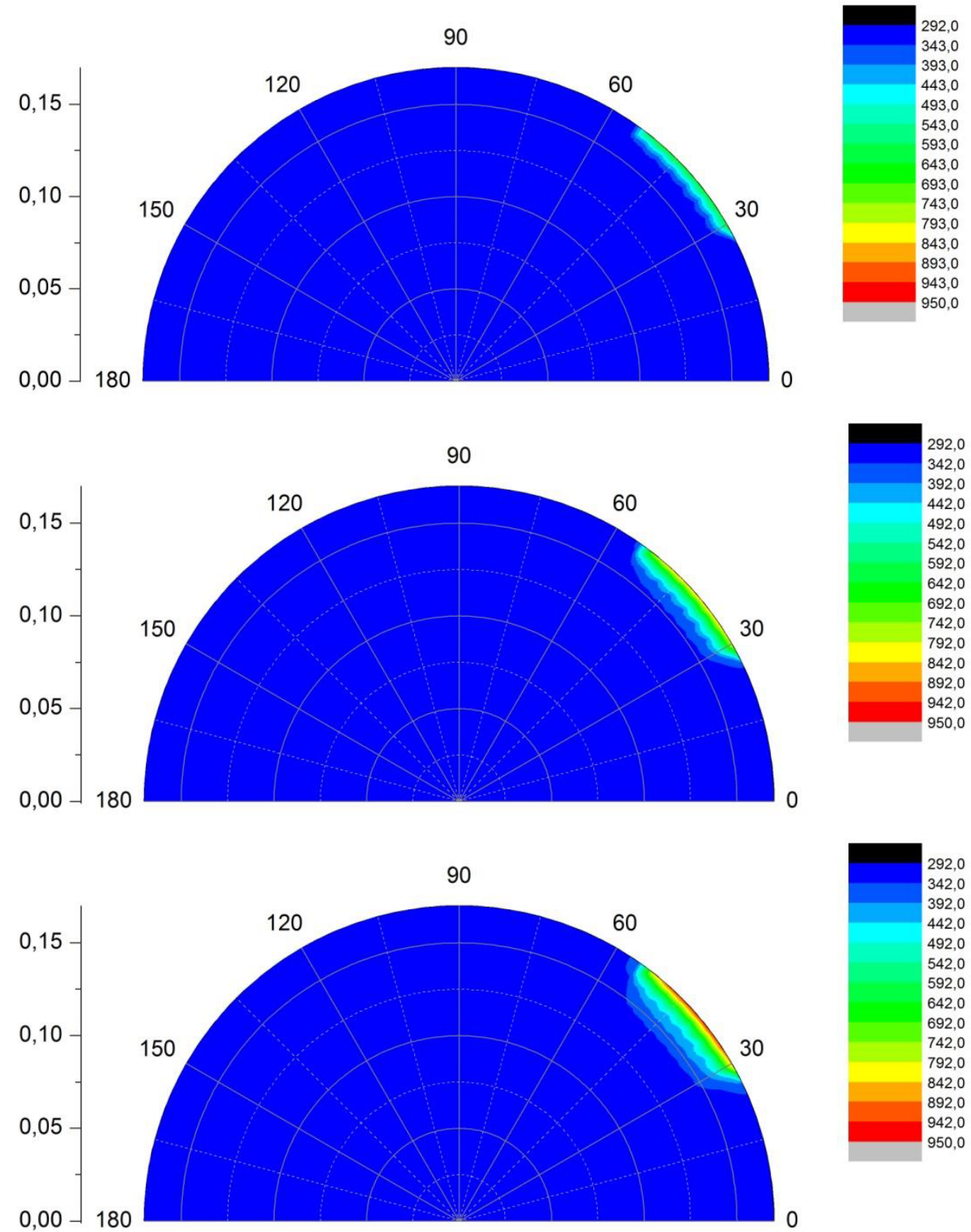

90

Figure 2. Distribution of temperatures in layered structure of coniferous tree during time moments $t=150,400$, 600 with.

The analysis of the obtained distributions allows to ascertain, that eventually there is an intensive warming up, as bark layer, and as subcrustal zone of coniferous tree trunk at the influence of radiation from forest fire front.

In the present work short-term enough influence of radiation from forest fire front (some minutes) on a tree trunk was accepted. This assumption corresponds to the real scenario of behavior of forest fire and characteristic speeds of distribution of a forward edge of forest fire on a large forest with coniferous trees.

Data on conditions of thermal defeat of coniferous tree trunk in subcrustal zone presented in tables 1,2 . The analysis of tables allows to draw the conclusion, that longer influence of radiation from 
forest fire leads to thermal defeat of subcrustal zone at smaller distances from a fire and density of thermal radiation. Logical the conclusion serves that fact, that advancement of an edge of forest fire on more short distance from a concrete tree raises probability of a thermal trauma of this tree. The quantitative analysis shows, that at short-term influence (to $250 \mathrm{~s}$ ) the critical distance from a fire edge makes 6 meters and less. While at longer influence thermal defeat is possible already on distance of 8-10 meters from a forest fire edge. In both cases thermal defeat of tree trunk tissues accompanied by pyrolysis of material of the subcrustal zone. In a consequence it is possible drying and mortality of such trees. It is necessary to notice, that is necessary to carry out in more details research of heat transfer at rather not high and average values of density of a thermal flux from fire front. Also it is possible to expect, that thermal damage to a reality will be characteristic for greater quantities of trees, rather than what can be defined on satellite data of the high resolution (burnt contours) $[11,12]$.

Table 1. Conditions of thermal defeat of a tree trunk at influence time $t=250$ with. Surface forest fire of high intensity [10].

\begin{tabular}{|l|l|l|l|l|}
\hline $\begin{array}{l}\text { Number of } \\
\text { computing } \\
\text { experiment }\end{array}$ & $\begin{array}{l}\text { Distance from an } \\
\text { edge of a fire to a } \\
\text { tree, } \mathrm{m}\end{array}$ & $\begin{array}{l}\text { Value of a radiant } \\
\text { thermal flux, } \\
\mathrm{kW} / \mathrm{m}^{2}\end{array}$ & $\begin{array}{l}\text { Pyrolysis of wood } \\
\text { in subcrustal zone }\end{array}$ & $\begin{array}{l}\text { Thermal defeat of a } \\
\text { tree }\end{array}$ \\
\hline 1 & 12 & 11,46 & no & no \\
\hline 2 & 8 & 35 & no & no \\
\hline 3 & 6 & 61,16 & yes & yes \\
\hline 4 & 4 & 106,87 & yes & yes \\
\hline 5 & 2 & 186,76 & yes & yes \\
\hline
\end{tabular}

Table 2. Conditions of thermal defeat of a tree trunk at influence time $\mathrm{t}=500$ with. Local forest fire of high intensity [10].

\begin{tabular}{|l|l|l|l|l|}
\hline $\begin{array}{l}\text { Number of } \\
\text { computing } \\
\text { experiment }\end{array}$ & $\begin{array}{l}\text { Distance from an } \\
\text { edge of a fire to a } \\
\text { tree, } \mathrm{m}\end{array}$ & $\begin{array}{l}\text { Value of a radiant } \\
\text { thermal flux, } \\
\mathrm{kW} / \mathrm{m}^{2}\end{array}$ & $\begin{array}{l}\text { Pyrolysis of wood } \\
\text { in subcrustal zone }\end{array}$ & $\begin{array}{l}\text { Thermal defeat of a } \\
\text { tree }\end{array}$ \\
\hline 1 & 12 & 11,46 & no & no \\
\hline 2 & 8 & 35 & yes & yes \\
\hline 3 & 6 & 61,16 & yes & yes \\
\hline 4 & 4 & 106,87 & yes & yes \\
\hline 5 & 2 & 186,76 & yes & yes \\
\hline
\end{tabular}

\section{Conclusion}

Thus, the two-dimensional mathematical model of thermal influence of radiation from forest fire front on coniferous trees developed. Research of heat transfer in layered structure of tree trunk at influence of local forest fire of high intensity on the basic laws carried out. As it has been told above, development of similar models opens prospects to creation of new generation of information systems on the basis of the determined mathematical models. Development of the complex deterministicprobabilistic approach of an estimation of ecological consequences of forest fires with attraction of results from prognostic modeling of forest fire danger [13-15], mathematical models of influence of forest fires on the human $[16,17]$ and modern information technologies $[18,19]$ is possible

\section{References}

1. Byram G.M. Combustion of forest fuels//Forest fire control and use (Ed. K. P. Davis, 1959)

2. Laurance W.F., Delamonica P., Laurance S.G., Vasconcelos, H., Lovejoy T.E., Nature, 404, 836 (200).

3. Mesquita R.C.G., Delamonica P., Laurance W.F. Biological Conservation, 91, 129 (1999) 
4. Yankovich, E.P., Baranovskiy, N.V., Yankovich, K.S. ArcGIS for assessment and display of the probability of forest fire danger, IFOST 2014, 222 (2014)

5. Barlow J., Peres C.A. Philosophical Transactions of the Royal Society B Biological sciences, 359, 367 (2004)

6. Uhl C., Kauffman J.B. Ecology, 71, 437 (1990)

7. Kuznetsov G.V., Baranovsky N.V. EPJ Web of Conferences, 76, 01028 (2014)

8. Kuznetsov G.V., Baranovsky N.V., Barakhnin V.B. EPJ Web of Conferences, 82, 01019 (2015)

9. Samarskiy A.A., Nikolaev E.S. Method of the decision of the mesh equations (1978) (In Russian)

10. Valendik E.N., Kosov I.V. Siberian Ecological Journal, 6, 517 (2008) (In Russian)

11. Fraser R. H., Li Z. Remote Sensing of Environment, 82, 95 (2002)

12. Zhang Y.-H., Wooster M. J., Tutubalina O., Perry G. L. W. Remote Sensing and Environment, 87, 1 (2003)

13. Grishin A.M., Baranovskii N.V. Inzhenerno-Fizicheskii Zhurnal, 76, 166 (2003)

14. Baranovskii N.V., Ni A.E. Journal of Engineering Physics and Thermophysics, 87, 1438 (2014)

15. Baranovskiy N.V., Nee A.E. EPJ Web of Conferences, 82, (Paper 01004) (2015)

16. Korobkina D.V., Baranovskiy N.V. MATEC Web of Conferences, 19, (Paper 01035) (2014)

17. Baranovskiy N.V., Solodkin A.S. MATEC Web of Conference, 23, (Paper 01008) (2015)

18. Baranovskiy N.V., Yankovich E.P. Journal of Automation and Information Sciences, 47, 11 (2015)

19. Baranovskiy N.V. Cybernetics and Systems Analysis, 51, 471 (2015) 